\title{
Increased sympathetic activity in normotensive offspring of malignant hypertensive parents compared to offspring of normotensive parents
}

\author{
H.F. Lopes ${ }^{1}$, F.M. Consolim-Colombo ${ }^{1}$, J.A.S. Barreto-Filho², G.M.G. Riccio ${ }^{1}$, \\ C.E. Negrão ${ }^{1}$ and E.M. Krieger ${ }^{1}$ \\ ${ }^{1}$ Instituto do Coração, Faculdade de Medicina, Universidade de São Paulo, São Paulo, SP, Brasil \\ ${ }^{2}$ Faculdade de Medicina, Universidade Federal do Sergipe, São Cristóvão, SE, Brasil
}

Correspondence to: H.F. Lopes, Av. Dr. Eneas de Carvalho Aguiar, 44, 05403-000 São Paulo, SP, Brasil Fax: +55-11-3069-5948. E-mail: hipheno@incor.usp.br

\begin{abstract}
Malignant hypertension seems to be the consequence of very high blood pressure. Furthermore, an increase in sympathetic and renin-angiotensin system activity is considered to be the main mechanisms producing malignant hypertension. In the present study, 10 offspring of malignant hypertensive $(\mathrm{OMH})$ parents (age $28 \pm 5$ years, 7 males, 3 females, 2 white and 8 non-white) and 10 offspring of normotensive (ONT) parents (age $28 \pm 6$ years, 2 males, 8 females, 3 white and 7 non-white) were evaluated. The OMH group had significantly higher $(P<0.05)$ casual blood pressure $(125 \pm 10 / 81 \pm 5 \mathrm{mmHg})$ compared with ONT $(99 \pm 13 / 67$ $\pm 5 \mathrm{mmHg}$ ). The increase in blood pressure was greater in OMH ( $\triangle \mathrm{SBP}=17 \pm 2 v s \Delta \mathrm{SBP}=9 \pm 1 \mathrm{mmHg}$ in ONT) during cold pressor testing, but they had a lower increase in heart rate $(\Delta \mathrm{HR}=13 \pm 2 v s \Delta \mathrm{HR}=20 \pm 3 \mathrm{bpm}$ in ONT) during isometric exercise (handgrip test). Sympathetic activity, measured by microneurography, was significantly higher $(P<0.05)$ before exercise in $\mathrm{OMH}(17 \pm 6$ vs $11 \pm 4 \mathrm{burst} / \mathrm{min}$ in ONT) and exhibited a greater increase $(\Delta=18 \pm 10 \mathrm{vs} \Delta=8 \pm 3 \mathrm{burst} / \mathrm{min}$ in ONT) during isometric exercise. This study showed increased sympathetic activity in $\mathrm{OMH}$ before exercise and a greater response during isometric exercise, suggesting an autonomic abnormality before exercise and a greater sympathetic response to physical stress in OMH compared to ONT.
\end{abstract}

Key words: Malignant hypertension; Offspring of malignant hypertensive parents; Sympathetic activity; Microneurography

Publication supported by FAPESP.

Received September 17, 2007. Accepted August 19, 2008

Marked elevation in blood pressure, lesions in arterial walls, and funduscopic findings, such as arteriolar spasm, retinal hemorrhages, and fundamental edema, characterize malignant hypertension. This is an important health problem, mainly in underdeveloped countries. The origin of malignant hypertension is unknown. Beilin et al. (1) suggest that it is a consequence of very high blood pressure. Whether it has a genetic predisposition has not been determined. Moreover, there are indications that any form of hypertension may progress to the malignant hypertensive phase (2). The systemic effects involved in the mechanisms of malignant hypertension include an increase in sympathetic and renin-angiotensin system activities (3). Patients with malignant hypertension not receiving adequate antihypertensive treatment will experience injury to several target organs and complications, such as hemorrhage and papilla edema in the funduscopy, left ventricular hypertrophy, renal failure, and heart failure. Also, mortality in one year is very high (4). Our group has demonstrated that offspring of hypertensive parents have increased blood pressure early in life compared with offspring of normotensive parents (5). It has also been shown that offspring of hypertensive parents compared with offspring of normotensive parents have higher plasma catecholamine levels, 

norepinephrine (6-9), suggesting increased sympathetic activity in this population. However, no data are available regarding sympathetic activity in offspring of malignant hypertensive parents. Therefore, the aim of this study was to evaluate the sympathetic activity in normotensive offspring of malignant hypertensive parents before exercise and in response to 2 stress tests, i.e., the cold pressor test and isometric exercise (handgrip).

Twenty subjects, 10 offspring of malignant hypertensive parents $(\mathrm{OMH})$ and 10 offspring of normotensive parents (ONT), were evaluated. They were matched for age, race, and body mass index (BMI). Malignant hypertension for the ization criteria as the presence of grades III and IV on funduscopy (Keith-Wagener classification). All subjects were followed up by medical staff at the Instituto do Coração (Universidade de São Paulo, São Paulo, SP, Brazil). Normotensive parents were recruited from the community (medical students' parents), and all had blood pressure (BP) $<140 / 90$ $\mathrm{mmHg}$ measured twice on 2 different occasions. Subjects signed an informed consent form before enrollment in this study. This study followed the guidelines and was approved by the Universidade de São Paulo Ethics Committee. Some volunteers in this study had already participated in another previously published study (5). All volunteers signed an informed consent form to participate in this study.

Office blood pressure was measured with a calibrated mercury sphygmomanometer with appropriately sized cuffs. Volunteers' blood pressure was measured in triplicate after at least a 2-min interval on 2 different occasions. and enhanced pressor response to increases in plasma parents was classified according to the World Health Organ-

Blood samples were drawn for the measurement of total cholesterol, LDL cholesterol, HDL cholesterol, triglycerides, glucose, uric acid, potassium, and sodium.

Cold pressor test. Subjects were instructed to immerse the hand of the uncuffed arm into a receptacle containing ice water at $1^{\circ} \mathrm{C}$ for $1 \mathrm{~min}$.

Isometric exercise. Subjects were instructed to squeeze a handgrip dynamometer set at $40 \%$ of total strength of the dominant arm for $90 \mathrm{~s}$.

Three minutes from the baseline period and $2 \mathrm{~min}$ including the stimulus period were considered for analysis for the cold pressor test and isometric exercise. Continuous beat-to-beat BP and heart rate $(\mathrm{HR})$ were measured noninvasively with a digital plethysmograph (Ohmeda 2300, Finapres, USA).

Microneurography. Muscle sympathetic nerve activity (MSNA) was recorded directly by microneurography. Briefly, a tungsten microelectrode $(200 \mu \mathrm{m}$ wide, tapering to an uninsulated tip of $1-5 \mu \mathrm{m}$ ) was inserted into a muscle fascicle of the common peroneal nerve, posterior to the fibular head and was adjusted until a spontaneous MSNA record was obtained. The recorded signal was fed to a preamplifier (gain: 1000), an amplifier (variable gain: 40$60)$, and a band pass filter $(700-2000 \mathrm{~Hz})$. The signal was then integrated to obtain a mean voltage display of MSNA neurograms (time constant: $0.1 \mathrm{~s}$ ). MSNA was counted in terms of burst frequency [(burst/min) and (burst/100 heart beats)]. MSNA was used to evaluate resting muscle sympathetic nerve activity in both groups before and during the cold pressor test and isometric exercise.

All values are reported as means \pm SD. Non-numeric variables like gender and race were compared using the chi-

Table 1. Body mass index and biochemistry of offspring of malignant hypertensive parents $(\mathrm{OMH})$ and offspring of normotensive parents (ONT).

\begin{tabular}{lcc}
\hline Variables & OMH & ONT \\
\hline Systolic blood pressure $(\mathrm{mmHg})$ & $124 \pm 10$ & $99 \pm 13^{*}$ \\
Diastolic blood pressure $(\mathrm{mmHg})$ & $81 \pm 5$ & $67 \pm 5^{*}$ \\
Heart rate $(\mathrm{bpm})$ & $68 \pm 10$ & $65 \pm 5$ \\
Body mass index $\left(\mathrm{kg} / \mathrm{m}^{2}\right)$ & $24.0 \pm 4.4$ & $22.0 \pm 1.7$ \\
Total cholesterol $(\mathrm{mg} / \mathrm{dL})$ & $150.5 \pm 18.1$ & $147.9 \pm 22.5$ \\
HDL cholesterol $(\mathrm{mg} / \mathrm{dL})$ & $43.3 \pm 7.3$ & $48.8 \pm 7.5$ \\
LDL cholesterol $(\mathrm{mg} / \mathrm{dL})$ & $94.3 \pm 18.2$ & $89.8 \pm 16.5$ \\
Triglycerides $(\mathrm{mg} / \mathrm{dL})$ & $65.1 \pm 26.0$ & $58.2 \pm 14.1$ \\
Glucose $(\mathrm{mg} / \mathrm{dL})$ & $76.5 \pm 11.7$ & $80.7 \pm 6.3$ \\
Uric acid $(\mathrm{mg} / \mathrm{dL})$ & $4.4 \pm 1.1$ & $3.5 \pm 1.0$ \\
Sodium $(\mathrm{mEq} / \mathrm{L})$ & $138.6 \pm 1.6$ & $138.4 \pm 1.1$ \\
Potassium $(\mathrm{mEq} / \mathrm{L})$ & $3.9 \pm 0.2$ & $4.0 \pm 0.2$ \\
Urea $(\mathrm{mg} / \mathrm{dL})$ & $26.2 \pm 3.1$ & $24.3 \pm 3.2$ \\
Creatinine $(\mathrm{mg} / \mathrm{dL})$ & $1.0 \pm 0.2$ & $1.2 \pm 1.0$
\end{tabular}

Data are reported as mean \pm SD for 10 subjects in each group. ${ }^{*} \mathrm{P}<0.05$ compared to $\mathrm{OMH}$ (Student unpaired $t$-test). square test. The unpaired Student $t$-test was used to compare numerical variables, such as age, $\mathrm{BP}, \mathrm{HR}$, and biochemical values between groups. Ageneral linear model for repeated measures was used to compare BP and HR changes during cold pressor testing and isometric exercise. The SPSS/PC 10.0 statistical software was used to perform the statistical analysis. A value of $\mathrm{P}<0.05$ was considered to be statistically significant.

Twenty subjects were evaluated: $10 \mathrm{OMH}$ (age $28 \pm 5$ years, 7 males, 3 females, 2 white and 8 non-white) and 10 ONT (age $28 \pm 6$ years, 2 males, 8 females, 3 white and 7 nonwhite). The $\mathrm{OMH}$ group had higher $\mathrm{BP}$ compared with the ONT group, although the values were still within the normal range for both groups. $\mathrm{HR}, \mathrm{BMI}$ and biochemistry were similar in both groups (Table 1). There was no correlation 
between BP, BMI, and MSNA before exercise or during stimuli. Systolic BP increased significantly during the cold pressor test in both groups, with a greater increase $(\mathrm{P}<$ $0.05)$ in $\mathrm{OMH}(\Delta$ systolic $\mathrm{BP}=17 \pm 2 \mathrm{mmHg}$ ) compared with ONT ( $\Delta$ systolic BP $=9 \pm 1 \mathrm{mmHg}$ ). Diastolic BP variation did not differ between $\mathrm{OMH}$ ( $\Delta$ diastolic $\mathrm{BP}=10 \pm 1 \mathrm{mmHg}$ ) and ONT ( $\Delta$ diastolic BP $=8 \pm 1 \mathrm{mmHg}$ ). The HR increased similarly during cold pressor testing in $\mathrm{OMH}(\Delta \mathrm{HR}=9 \pm 1$ bpm) and in ONT ( $\Delta \mathrm{HR}=7 \pm 1 \mathrm{bpm})$. Systolic BP increased significantly during isometric exercise in $\mathrm{OMH}(\Delta$ systolic BP $=16 \pm 3 \mathrm{mmHg}$ ) compared with ONT ( $\Delta$ systolic $\mathrm{BP}=14 \pm 2 \mathrm{mmHg}$ ), but the increase did not differ significantly between the groups. Diastolic BP of both groups also increased but did not differ significantly between $\mathrm{OMH}$ ( $\Delta$ diastolic BP $=11 \pm 2 \mathrm{mmHg}$ ) and ONT ( $\Delta$ diastolic BP $=$ $11 \pm 1 \mathrm{mmHg}$ ). The $\mathrm{HR}$ also increased during isometric exercise in $\mathrm{OMH}(\Delta \mathrm{HR}=13 \pm 2 \mathrm{bpm})$ and in ONT $(\Delta \mathrm{HR}=$ $20 \pm 3 \mathrm{bpm})$, and the increase was significantly higher $(\mathrm{P}<$ $0.05)$ in the ONT group. The sympathetic activity before exercise, evaluated by microneurography, was higher $(\mathrm{P}<$ $0.05)$ in the OMH compared with the ONT group (17 \pm 6 vs $11 \pm 4$ burst/min and $25 \pm 10$ vs $17 \pm 6$ burst/100 heart beats, respectively). The sympathetic activity increased significantly $(\mathrm{P}<0.05)$ during cold pressor testing in $\mathrm{OMH}$ ( $\Delta=11 \mathrm{burst} / \mathrm{min}$ and $12 \mathrm{burst} / 100$ heart beats) and ONT ( $\Delta=8 \mathrm{burst} / \mathrm{min}$ and $9 \mathrm{burst} / 100$ heart beats). The sympathetic activity increased significantly $(P<0.05)$ in $\mathrm{OMH}(\Delta$ $=14 \mathrm{burst} / \mathrm{min}$ and 14 burst $/ 100$ heart beats) and ONT $(\Delta$ $=6 \mathrm{burst} / \mathrm{min}$ and 3 burst $/ 100$ heart beats) during the isometric exercise, and the increase was significantly higher $(\mathrm{P}<0.05)$ in the $\mathrm{OMH}$ group. Figure 1 shows MSNA and beat-to-beat BP before and during isometric exercise in 2

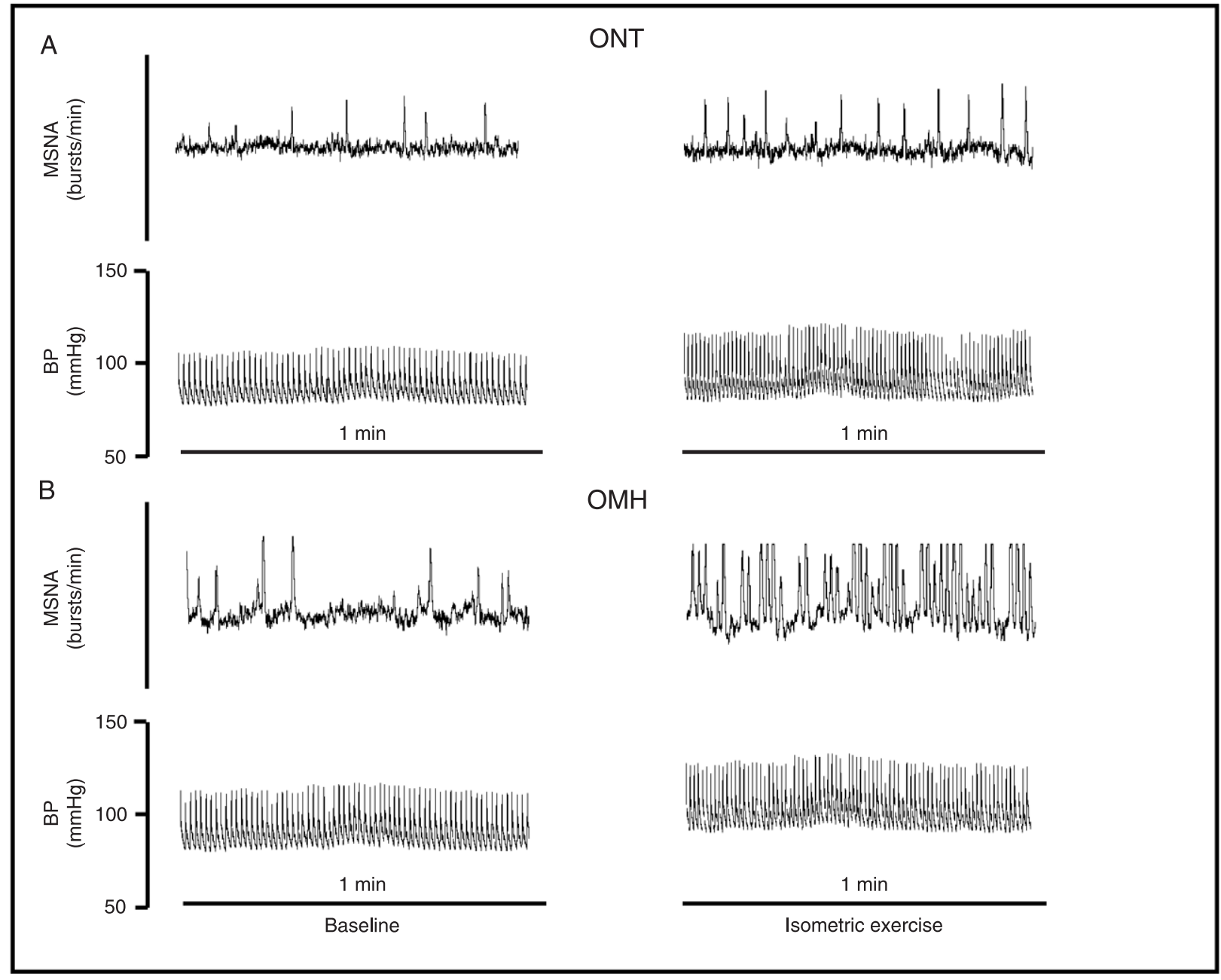

Figure 1. Muscle sympathetic nerve activity (MSNA) and beat-to-beat blood pressure (BP) before and during isometric exercise of a 23-year-old female offspring of normotensive parents (ONT) (A) and a 22-year-old female offspring of malignant hypertensive parents $(\mathrm{OMH})(\mathrm{B})$. Velocity $=10 \mathrm{~mm} / \mathrm{s}$. 
subjects, one ONT and another $\mathrm{OMH}$.

In this study, the normotensive $\mathrm{OMH}$ had higher $\mathrm{BP}$, higher sympathetic activity before exercise, a greater increase in BP during the cold pressor test, and a greater increase in sympathetic activity during isometric exercise compared with ONT. Subjects were matched for BMI, and there were no correlations between MSNA and BMI.

While studying healthy subjects, Scherrer et al. (10) demonstrated a correlation between BMI, percent body fat, and MSNA. However, they included overweight and obese subjects in their study, whereas the average BMI in the present study was normal. Although the $\mathrm{OMH}$ and ONT had similar age and $\mathrm{BMI}, \mathrm{OMH}$ had higher $\mathrm{BP}$. These results suggest that the higher $\mathrm{BP}$ in the normotensive $\mathrm{OMH}$ is probably determined by increased sympathetic activity. Studying normotensive offspring of hypertensive parents, we found that they have higher casual BP and also higher plasma levels of catecholamines before exercise (7). Ferrier et al. (6) also found higher plasma norepinephrine before exercise and an elevated overall rate of spillover of norepinephrine to plasma in the offspring of hypertensive parents. In our study, both groups had an increase in systolic and diastolic BP during cold pressor testing and isometric exercise; however, the $\mathrm{OMH}$ group had a greater response compared with the ONT group, suggesting a greater reactivity of the vessels to physical stress. The greater response of BP to cold pressor testing in offspring of hypertensive parents has already been reported $(11,12)$. However, no study has evaluated the BP response to cold pressor testing in $\mathrm{OMH}$. On the other hand, HR response to cold pressor testing did not differ between groups, suggesting that the larger increase in systolic $\mathrm{BP}$ exhibited by $\mathrm{OMH}$ is related to vascular response, and not to $\mathrm{HR}$ response. The BP response to isometric exercise was similar for both groups; however, the change in HR was greater in ONT. In this case, the greater response of the heart to this kind of stress test indicated that the pattern of sympathetic activation varied according to the stress stimulus.

Sympathetic activity before exercise, measured by microneurography, was greater in the $\mathrm{OMH}$ group, which differs from results of other studies that show no difference in sympathetic activity before exercise measured by microneurography $(13,14)$. Interestingly, Noll et al. (15) did not find differences in sympathetic activity before exercise in offspring of hypertensive parents, but found a greater increase in sympathetic activity during mental stress. In the present study, sympathetic activity was greater in $\mathrm{OMH}$ before exercise and increased significantly more during the cold pressor test and isometric exercise than in ONT. Considering the interindividual differences in sympathetic control of the cardiovascular system at rest and in response to sensory stimulation (16), the weak part of this study is the relatively small number of subjects. However, the 2 groups were totally distinct according to genetic background. Unfortunately, no study involving $\mathrm{OMH}$ has been previously published that we can compare our results to. Because the HR increased more in the ONT group during isometric exercise, it seems that different degrees of regional activation of the sympathetic system are elicited by different stimuli. The greater increase in sympathetic activity in $\mathrm{OMH}$ suggests a possible mechanism for future hypertension in this population. These findings suggest that the $\mathrm{OMH}$ subjects should be a target for better early assistance concerning lifestyle.

Normotensive offspring of parents with malignant hypertension had higher casual BP, higher sympathetic activity before exercise, and a greater increase in sympathetic activity during isometric exercise compared with offspring of normotensive parents, suggesting an autonomic abnormality before exercise and a greater sympathetic response to physical stress in OMH compared to ONT.
1. Beilin LJ, Goldby FS, Mohring J. High arterial pressure versus humoral factors in the pathogenesis of the vascular lesions of malignant hypertension. Clin Sci Mol Med 1977; 52: 111-117.

2. Gavras H, Brunner HR, Laragh JH, Vaughan ED Jr, Koss M, Cote LJ, et al. Malignant hypertension resulting from deoxycorticosterone acetate and salt excess: role of renin and sodium in vascular changes. Circ Res 1975; 36: 300-309.

3. Kincaid-Smith P. Malignant hypertension. J Hypertens 1991; 9: 893-899.

4. Kaplan N. Primary hypertension: pathogenesis. In: Kaplan N (Editor), Clinical hypertension. Baltimore: Williams \&
Wilkins; 1998. p 444.

5. Lopes HF, Bortolotto LA, Szlejf C, Kamitsuji CS, Krieger EM. Hemodynamic and metabolic profile in offspring of malignant hypertensive parents. Hypertension 2001; 38: 616-620.

6. Ferrier $\mathrm{C}, \mathrm{Cox} \mathrm{H}$, Esler M. Elevated total body noradrenaline spillover in normotensive members of hypertensive families. Clin Sci 1993; 84: 225-230.

7. Lopes HF, Silva HB, Consolim-Colombo FM, Barreto Filho JA, Riccio GM, Giorgi DM, et al. Autonomic abnormalities demonstrable in young normotensive subjects who are children of hypertensive parents. Braz J Med Biol Res 2000; 
33: $51-54$.

8. Bianchetti MG, Weidmann P, Beretta-Piccoli C, Rupp U, Boehringer $\mathrm{K}$, Link $\mathrm{L}$, et al. Disturbed noradrenergic blood pressure control in normotensive members of hypertensive families. Br Heart J 1984; 51: 306-311.

9. De Lima JJ, Dias MM, Bernardes-Silva H, Bellotti G. Pressor response to norepinephrine in essential hypertension. A study in families. Hypertension 1990; 15 (2 Suppl): I-137-I139.

10. Scherrer U, Randin D, Tappy L, Vollenweider P, Jequier E, Nicod P. Body fat and sympathetic nerve activity in healthy subjects. Circulation 1994; 89: 2634-2640.

11. Walia V, Ahuja L, Kaur P. Cardiovascular reactivity to cold pressor test in offspring of normotensive \& hypertensive parents. Indian J Med Res 1994; 99: 38-41.

12. Kasagi F, Akahoshi M, Shimaoka K. Relation between cold pressor test and development of hypertension based on 28year follow-up. Hypertension 1995; 25: 71-76.
13. Yamada $Y$, Miyajima E, Tochikubo O, Matsukawa $T$, Shionoiri $\mathrm{H}$, Ishii $\mathrm{M}$, et al. Impaired baroreflex changes in muscle sympathetic nerve activity in adolescents who have a family history of essential hypertension. J Hypertens Suppl 1988; 6: S525-S528.

14. Hausberg M, Sinkey CA, Mark AL, Hoffman RP, Anderson EA. Sympathetic nerve activity and insulin sensitivity in normotensive offspring of hypertensive parents. Am J Hypertens 1998; 11: 1312-1320.

15. Noll G, Wenzel RR, Schneider M, Oesch V, Binggeli C, Shaw $S$, et al. Increased activation of sympathetic nervous system and endothelin by mental stress in normotensive offspring of hypertensive parents. Circulation 1996; 93: 866869.

16. Wallin BG. Interindividual differences in muscle sympathetic nerve activity: a key to new insight into cardiovascular regulation? Acta Physiol 2007; 190: 265-275. 